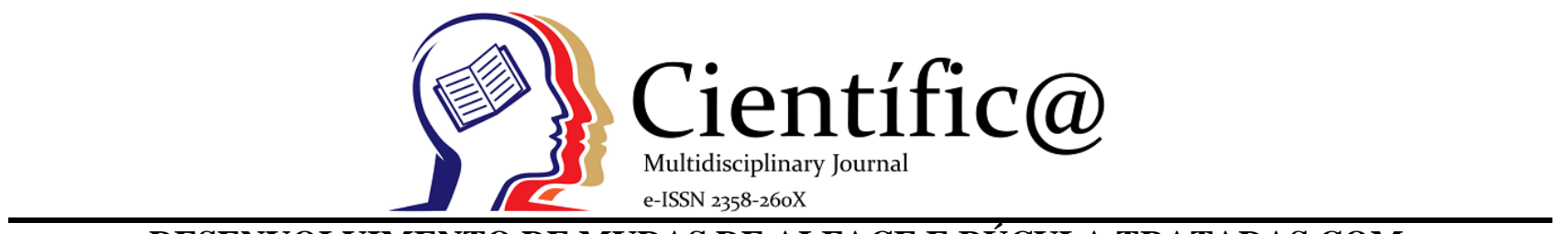

\title{
DESENVOLVIMENTO DE MUDAS DE ALFACE E RÚCULA TRATADAS COM BIOFERTILIZANTE DE EXTRATO DE ALGAS
}

\section{EVALUATION OF THE DEVELOPMENT OF LETTUCE AND RUCULA SEEDLINGS TREATED WITH ALGAE EXTRACT BIOFERTILIZER}

\author{
Ariel Dinz Crivelare ${ }^{1}$, Jonas de Sousa Corrêa ${ }^{2}$, Cristiano Pereira da Silva $^{3}$
}

\footnotetext{
${ }^{1}$ Acadêmico do Curso de Agronomia da Universidade Estadual de Mato Grosso do Sul. Unidade de Aquidauana/MS. ${ }^{2}$ Docente da Faculdade Estácio de Sá, Curso de Engenharia Ambiental e Sanitária de Campo Grande.

${ }^{3}$ Docente do Curso de Agronomia da Universidade Estadual de Mato Grosso do Sul. Unidade de Aquidauana/MS.
}

\section{Info}

Recebido: 04/2021

Publicado: 06/2021

DOI: 10.37951/2358-260X.2021v8i1.5652

ISSN: 2358-260X

\section{Palavras-Chave}

biofertilizante, algas, hortaliças.

Keywords:

biofertilizer, alga, vegetables.

\begin{abstract}
Resumo
Tendo em vista a expansão do uso de produtos alternativos como os biofertilizantes no Brasil, o presente trabalho têm como principal objetivo verificar os efeitos do biofertilizante a base de extrato de alga no desenvolvimento de mudas de alface (Lactuca sativa L.) e rúcula (Eruca sativa M.). O experimento foi conduzido nas dependência da Universidade Estadual de Mato Grosso do Sul, UEMS, Unidade de Aquidauana/MS no período de agosto a dezembro de 2019. O biofertilizante é composto por extrato de diferentes espécies de algas, retirada dos tanques coletores de descarte de dejetos orgânicos dos coxos de ovinos e suínos da área experimental da zootecnia. $O$ biofertilizante foi preparado, com a homogeneização e diluição em
\end{abstract} água, perfazendo duas concentrações, 0,25 (25\%) e 0,50 (50\%), sendo aplicado nas plantas em intervalos de 15 em 15 dias. O delineamento experimento foi 3 tratamentos 0\%, 25\% e 50\% com 12 repetições por parcela. Dentre os parâmetros avaliativos destacam-se: comprimento da raiz, altura da planta, número de folhas, área foliar e peso fresco. Dentre os resultados obtidos destacam-se como melhores resultados o tratamento em que se utilizou a concentração de 50\% do extrato do biofertilizante, para comprimento da raiz, altura da planta, área foliar e peso fresco, quando comparado com o tratamento controle.

\begin{abstract}
In view of the expansion of the use of alternative products such as biofertilizers in Brazil, the present work has as main objective to verify the effects of biofertilizer based on seaweed extract on the development of lettuce (Lactuca sativa L.) and arugula (Eruca seedlings) sativa M.). The experiment was carried out in the premises of the State University of Mato Grosso do Sul, UEMS, Aquidauana Unit / MS from August to December 2019. The biofertilizer is composed of extract from different species of algae, taken from the collection tanks for the disposal of organic waste from lame sheep and pigs from the experimental area of zootechnics. The biofertilizer was prepared, with homogenization and dilution in water, making two concentrations, $0.25(25 \%)$ and $0.50(50 \%)$, being applied to the plants at intervals of 15 in 15 days. The experiment design was 3 treatments $0 \%, 25 \%$ and $50 \%$ with 12 repetitions per plot. Among the evaluative parameters, the following stand out: length of the root, height of the plant, number of leaves, leaf area and fresh weight. Among the results obtained, the treatment with the concentration of $50 \%$ of the biofertilizer extract stands out as the best results, for root length, plant height, leaf area and fresh weight, when compared to the control treatment.
\end{abstract}

\section{Introdução}

A produção de hortaliças é uma atividade em constante expansão em todo território brasileiro, com o cultivo em hortas urbanas, bairros rurais e sítios em torno das cidades. As hortaliças fazem parte das refeições diárias dos brasileiros, importante fonte de sais minerais e vitaminas. Sua produção é alta em muitas regiões, com rápido escoamento de sua produção, chegando as feiras livres, mercearias, quitandas, e supermercados, praticamente renovado todos os dias (ARAUJO et al.,2012). 
Segundo Amorin Neto (2019) e Bonett et al. (2019) a produção de culturas olerícolas são realizadas por agricultores familiares, pois esse tipo de cultivo utiliza-se de pouco espaço, pouco insumo, e por ter um ciclo bastante curto. No Brasil, as hortaliças são cultivada tradicionalmente por pequenos produtores, constituindo-se, dessa forma, uma cultura de grande importância econômica e social, garantindo a empregabilidade e o giro econômico de muitos municípios. A alface (Lactuca sativa L.) é uma das hortaliças folhosas de maior importância comercial e de maior consumo em todo o mundo. No Brasil, figura entre as principais hortaliças, no que se refere à produção, à comercialização e ao valor nutricional.

Preferida dos pequenos agricultores, por ser uma cultura de fácil manejo, com uma ampla adaptação climática, ciclo curto de vida, permitindo vários plantios consecutivamente ao ano, não necessita de altos custos para sua produção, tendo pouca susceptibilidade a pragas e doenças, garante uma produção sem grandes riscos de perdas econômicas. Com isso, o cultivo da hortaliça tem contribuído de forma considerável para a geração de empregos, estando inserida, principalmente, na agricultura familiar, como fonte de renda essencial para as famílias (RESENDE et al., 2012).

Outra hortaliça muito cultivada e de grande aceitação no mercado é a rúcula. A rúcula (Eruca sativa) foi introduzida no Brasil por imigrantes italianos, pelos quais ainda é muito apreciada. É mais consumida nas regiões Sul e Sudeste, entretanto, o seu consumo é crescente em outras regiões do país, por causa do seu sabor marcante em saladas junto a folhas mais suaves, na cobertura de pizzas, em molhos para massas e até mesmo em sopas (ALVES e SANTOS, 2018)

Pelo fator nutricional a rúcula vem se destacando entre as hortaliças no Brasil. Por mais que exista cultivares produtivas, o sistema radicular da rúcula é superficial, exigindo irrigação complementar. A rúcula é muito sensível ao déficit hídrico do solo e a irrigação é uma pratica indispensável para que a olerícola atinja bons níveis de produção (FERREIRA et al., 2014)

O emprego de fertilizantes e defensivos químicos em hortaliças é uma prática agrícola que traz resultados satisfatórios, porém deve-se levar em consideração a qualidade do produto, pois sabe-se que o uso desordenado desses produtos pode vir a prejudicar a saúde dos consumidores, além de onerar o custo de produção. Tendo em vista que o uso de produtos alternativos como os biofertilizantes vem crescendo em todo o Brasil. $\mathrm{Na}$ busca por insumos menos agressivos ao ambiente e que possibilitem o desenvolvimento de uma agricultura menos dependente de produtos industrializados, vários produtos têm sido lançados no mercado (GUERREIRO et al., 2011).

Em todo o Brasil, produtores buscam aumentar suas lavouras, e obter uma produtividade sustentável, aderindo tecnologias compostas por algas. Diferentes compostos extraídos de macro algas tem função protetora das plantas pertence à classe dos polissacarídeos, contendo uma enorme variação estrutural, com raros carboidratos e agrupamentos de sulfato (MACEDO, 2016).

Atualmente o Brasil é considerado um dos países que mais utilizam adubação química e controle químico na agricultura. Sendo assim, é importante visar um sistema de produção com o uso de produtos alternativos como os biofertilizantes, que são produtos biológicos a qual atuam de forma não poluidora, além de ter o custo muito baixo, fácil acesso e ser prático (OGAWA, 2012). De acordo Pereira et al., (2010), o uso de fertilizantes orgânicos é uma prática que está sendo cada vez mais utilizada pelos produtores, que utilizam materiais alternativos, como estercos de 
animais, materiais vegetais e sais minerais na sua formulação.

As hortaliças apresentam um bom desenvolvimento em solos estruturados, arejados, ricos em matéria orgânica e com adequada umidade. Solos compactados ou encharcados provocam diminuição na produtividade e aumentam as doenças nas plantas. São plantas com exigência em nitrogênio, cálcio, fósforo e potássio, tudo de forma equilibrada e não se desprezando a importância dos demais nutrientes (FILGUEIRA, 2008).

O Nitrogênio $(\mathrm{N})$ é o nutriente exigido em maior quantidade pela maioria das culturas, as doses adequadas de $\mathrm{N}$ favorecem o crescimento vegetativo, o acúmulo de massa e o aumento de aérea foliar, no entanto, o excesso pode ocasionar problemas, dentre os quais a perda da qualidade do produto. Devido à cultura ser composta basicamente por folhas, se concretiza a importância do nitrogênio (MALAVOLTA, 2006; FILGUElRA, 2008). Além de que na adubação de cobertura os fertilizantes mais usados são os nitrogenados e aqueles que dispõem da mistura com outros nutrientes (SOBREIRA FILHO, 2012).

Tendo em vista que o uso de produtos alternativos como os biofertilizantes vem crescendo em todo o Brasil, a busca por insumos menos agressivos ao ambiente e que possibilitem o desenvolvimento de uma agricultura menos dependente de produtos industrializados, vários produtores têm aderido ao uso de biofertilizantes na produção de hortaliças (DELEITO, et al. 2000).

Em todo o Brasil, produtores buscam aumentar suas lavouras, e obter uma produtividade sustentável, aderindo tecnologias compostas por algas. Diferentes compostos extraídos de macro algas tem função protetora das plantas pertence à classe dos polissacarídeos, contendo uma enorme variação estrutural, com raros carboidratos e agrupamentos de sulfato (MACEDO, 2016).

As algas são fontes de macro e micronutrientes (N, P, K, Ca, Cl, Mg, S, B, Mn e Zn), aminoácidos (alanina, ácido aspártico e glutâmico, glicina, isoleucina, leucina, lisina, metionina, fenilalanina, prolina, tirosina, triptofano e valina), citocininas, auxinas, e ácido abscísico, substâncias que vão atingir o metabolismo celular das plantas e reforçam o crescimento. As algas funcionam como bioestimulantes vegetais, e ainda de estimulantes naturais, sendo organismos autótrofos e fotossintetizantes que diferem das plantas por não formarem tecidos nem órgãos, ou seja, não possuem uma estrutura que divide raiz, caule e folha, podendo ser unicelulares ou pluricelulares (AMORIN NETO, 2019).

Pinto et al., (2010), a busca incessante por uma alimentação mais saudável, a exemplo das hortaliças folhosas que são consumidas in natura, vê-se a necessidade de um modelo de manejo que seja ecológico e economicamente viável para a produção dessa olerícola. Assim, a utilização de Extratos Concentrados de Algas Marinhas (ECAM's) se apresenta como item importante da alternativa para esse modelo de produção. Os ECAM's disponibilizam para as plantas, além dos macronutrientes $(\mathrm{N}, \mathrm{P}, \mathrm{K}, \mathrm{Ca}$, $\mathrm{Mg}, \mathrm{S}$ ) e micronutrientes (Cu, Zn, Mn, B e Co), aminoácidos, vitaminas (B1, B2, C e E) e hormônios como as citocininas, auxinas, giberelinas, betainas e laminarinas.

Segundo Coelho et al., (2012) os efeitos benéficos que as algas apresentam às plantas cultivadas está relacionado à sua capacidade de aumento na assimilação de nutrientes, do conteúdo de clorofila, da síntese de proteína, divisão celular, da ação positiva sobre o crescimento radicular e parte aérea, como a melhora da germinação das sementes. A espécie mais conhecida na composição de biofertilizzantes é a 
Ascophyllum nodosum sendo a mais utilizada para esses fins, com efeitos significativos no desenvolvimento de diferentes cultivares de hortaliças. As algas apresentam em sua constituição mais de 60 elementos químicos e bioestimulantes importantes, indutores de resistência, que ainda ajudam no transporte de micronutrientes, e vitaminas melhorando os processos fotossintéticos

As algas são portadoras de inúmeros grupos de compostos antioxidantes, substâncias que atingem o metabolismo celular das plantas e direciona para um aumento do crescimento, bem como ao impulso da produtividade (AMORIN NETO, 2019). Estudos tem demonstrado que a utilização do extrato de algas como biofertilizante é benéfica para o aumento da taxa de germinação, enraizamento, melhoria no desempenho e produtividade vegetal, resistência a estresses bióticos e abióticos. O uso de biofertilizantes ou bioestimulantes a base de extrato de algas está cada vez mais inserido, também, no cenário da agricultura orgânica (GARCIA et al., 2014; BRITO et al., 2017; AMORIN NETO, 2019).

Desta forma, com base nas propriedades e potenciais de biofertilizantes a base de algas para o desenvolvimento de mudas e plantas, o presente trabalho tem como objetivo avaliar os efeitos de diferentes concentrações de extratos de algas sob a produção de mudas de alface e rúcula

\section{Material e Métodos}

O experimento foi conduzido na Universidade Estadual de Mato Grosso do Sul, Unidade Universitária de Aquidauana/MS, situada entre as coordenadas 20²7'20" S, 5540'17" W e altitude de aproximadamente $191 \mathrm{~m}$, no período de agosto a dezembro de 2019. O clima da região é do tipo Aw segundo a classificação de Koppen, possuindo o verão chuvoso e no inverno encontra-se seco, com precipitação média anual de $1231 \mathrm{~mm}$, com temperaturas máximas e mínimas de 33 e $19^{\circ} \mathrm{C}$.

O delineamento experimental utilizado foi o inteiramente casualizado com 3 tratamentos e 12 repetições. Os tratamentos utilizados foram três concentrações $(0 \%, 25 \%$ e $50 \%$ do biofertilizante produzido na fazenda experimental da faculdade). O biofertilizante é composto por extrato de diferentes espécies de algas de água doce, retirada dos tanques coletores de descarte de dejetos orgânicos dos coxos de ovinos e suínos da área experimental da zootecnia. Para o preparo dos extrato de algas, foram cultivadas diferentes espécies de algas de água doce, em tanque aberto sem tratamento, gerados a partir da decomposição anaeróbia com tempo de retenção hidráulica de 120 dias a base de resíduos animais de suínos e ovino, perfazendo a proporção de $25 \%$ e $50 \%$ de concentrações.

O preparo do biofertilizante foi com base na trituração, filtração e homogeneização do extrato, composto por algas e rejeitos de suínos e ovinos, diluído em água e estocado em tanques de 50L. Logo após este preparo foram realizadas as aplicações do biofertilizante nas mudas de alface e rúcula. As sementes de alface e rúculas foram germinadas em bandejas de polietileno expandido, tamanho padrão de $54,5 \mathrm{~cm}$ de comprimento por $28 \mathrm{~cm}$ de largura, possuindo 200 células cada uma das células tem 2,3 centímetros de largura e 4 centímetros de altura.

Como substrato foram utilizada apenas um tipo de substrato comercial Plante Verde $\AA$ para todos os tratamentos. A composição químicas do substrato, será descrito a seguir: $\mathrm{pH}$ 5,6; Ca \%=0,82; $\mathrm{Mg} \%=$ 0,$17 ; \mathrm{K} \%=0,54 ; \mathrm{Al} \%=0,0 ;$ Matéria orgânica $\%=62$; Cinzas $\%=37,75$; e Umidade $\%=49,8$.

O tratamento controle ou testemunha (T0) foi realizada irrigação com regador com $0 \%$ de extratos de algas, contendo somente água. No tratamento 1 (T1) foi 
realizada a irrigação com 25\% do extrato de algas, ou seja, mediu-se no béquer $150 \mathrm{ml}$ de água e $50 \mathrm{ml}$ do biofertilizante de extrato de algas e rejeitos de suínos e ovinos. No tratamento 2 (T2) foi realizada a irrigação com 50\% do extrato de algas, ou seja, mediu-se no béquer $100 \mathrm{ml}$ de água e $100 \mathrm{ml}$ de algas e rejeitos de suínos e ovinos. Posteriormente as irrigações foram realizadas com regador duas vezes ao dia repetindo as mesmas condições e concentrações do biofertilizante de 15 em 15 dias durante os 60 dias de manutenção do cultivo e experimento.

As avaliações de acompanhamento do experimento foi quinzenal, sendo avaliadas as seguintes características: comprimento da parte área da planta, onde foi retirada a medida do colo até ápice da altura da última folha em centímetros $(\mathrm{cm})$, números de folhas, onde foram contadas todas as folhas verdadeiras, área foliar (cm) medindo a área da maior folha, em comprimento e largura. No final do experimento foram avaliados peso fresco e comprimento de raiz $(\mathrm{cm})$. Os dados obtidos foram submetidos à Análise de Variância (teste F) e os tratamentos comparados através do teste de Tukey, ao nível de $5 \%$ de probabilidade pelo programa SISVAR (FERREIRA, 2011).

\section{Resultados e Discussão}

De acordo com os resultados obtidos na Tabela 01, houve diferença significativa entre as concentrações do biofertilizantes nas mudas de rúculas, para o comprimento de raiz e altura de planta. Não foi possível observar diferença significativa para número de folhas.
Os resultados obtidos neste trabalho se assemelha ao observado por Pinto et al., (2010), com o extrato de alga no desenvolvimento de hortaliças, onde o diâmetro do caule das mudas tiverem resultados significativamente maiores quando comparados a testemunha, ficando evidente que as doses testadas do biofertilizante em aplicações foliares tiveram bons resultados. Um caule de maior diâmetro pode significar maior resistência da planta ao tombamento, e uma melhor qualidade final da hortaliça.

Santos et al., (2011) e Coelho et al, (2012) trabalhando com biofertilizantes a base de extrato de alga, perceberam efeito significativos no para comprimento da parte aérea e comprimento do sistema radicular um aumento de $13,28 \%$ e $27,45 \%$, respectivamente, em relação a testemunha, enquanto que no presente trabalho observou-se para as mesmas variáveis um crescimento de $15 \%$ e 3,81\% em relação a testemunha, para o cultivo de mudas de pimentão e tomate.

Em relação ao peso fresco Pinto et al. (2010) trabalhando com biofertilizantes a base de extrato de algo, não teve efeito significativo nas mudas iniciais de alface. Segundo os mesmos autores, o peso da matéria fresca da alface não diferiu significativamente quando se utilizou as diferentes doses do extrato de algas pulverizado sobre as folhas ou sobre o solo na menor dose, sendo estes, entretanto, superiores aos constatados quando se usou a maior dose sobre o solo e em relação ao controle.

Tabela 1. Valores de p - probabilidade para as variáveis de comprimento de raiz (CR), altura de planta (AP), número de folhas $(\mathrm{NF})$, área foliar (AF), peso fresco $(\mathrm{PF})$ no desenvolvimento inicial da cultura da rúcula (Eruca sativa $\mathrm{M})$ em diferentes doses de biofertilizante a base de algas, 15 DAE.

\begin{tabular}{lccccc}
\hline FV & CR $(\mathrm{cm})$ & AP $(\mathrm{cm})$ & NF & AF $(\mathrm{cm})$ & PF $(\mathrm{g})$ \\
\hline Doses do biofertilizante & $0,0015^{*}$ & $0,0001^{*}$ & $0,25^{\text {ns }}$ & $0,0001^{*}$ & $0,0012^{*}$ \\
\hline CV\% & 20,63 & 13,86 & 20,22 & 14,57 & 21,35 \\
Média geral & 4,93 & 6,99 & 2,47 & 6,78 & 8,25 \\
\hline
\end{tabular}

Valores de $\mathrm{p},\left(^{*}\right)$ significativo pelo teste $\mathrm{F}$ ao Nível de $5 \%$ de probabilidade, (ns) não significativo. 
Amorin Neto (2019), trabalhando com biofertilizante com extrato de alga no cultivo de mudas de tomate, verificou que o comprimento da parte aérea, o tratamento composto por plantas tratadas com $7 \%$ de extrato de algas sobressaiu estatisticamente em relação as demais tratamentos, apresentando $29,10 \%$ de aumento em relação a testemunha. Segundo o mesmo autor não houve efeito significativo de promoção de crescimento para o comprimento radicular e comprimento total das mudas de tomate.

$\mathrm{Na}$ Tabela 02 pode-se verificar que para o comprimento de raiz, altura da planta, área foliar e peso fresco as doses de 25\% e 50\% apresentaram maiores resultados, em relação ao cultivo sem a utilização da alga (testemunha ou controle) demonstrando o efeito positivo do biofertilizante no início do desenvolvimento das mudas de rúcula.

Segundo Albuquerque (2014) e Amorin Neto (2019), as algas são empregadas como estimulantes naturais, melhoramento as atividades fotossintéticas, absorção de nutrientes, desenvolvimento radicular, proteção vegetal contra fitopatógenos, produção de bioativos capazes de realizar a indução de resistência ao estresse e ataque de pragas nos vegetais, realçando o processo de germinação e enraizamento de plântulas. Este fato vem de encontro com os resultados obtidos na Tabela 02 , com resultados significativos na medida em que foram aumentando as concentrações do biofertilizante.

Vidal et al. (2012) avaliando o desenvolvimento inicial de mudas de rúcula em diferentes doses de biofertilizante urina de vaca, encontrou resultados menores que o encontrado no presente trabalho, o maior comprimento de raiz foi encontrado na concentração de $12 \%$ de urina de vaca com 4,84 cm. Por outro lado Oliveira et al. (2018) estudando adubação com fertilizante organomineral na produção de mudas de rúcula, encontrou resultados superiores $6,87 \mathrm{~cm}$ de comprimento de raiz.

Tabela 2. Comprimento de raiz (CR), altura de planta (AP), número de folhas (NF), área foliar (AF) e peso fresco (PF) no desenvolvimento inicial da cultura da rúcula (Eruca sativa $\mathrm{M}$ ) em diferentes doses de biofertilizante a base de algas. 15 DAE.

\begin{tabular}{cccccc}
\hline Doses Biofertilizante & CR $(\mathrm{cm})$ & AP $(\mathrm{cm})$ & NF & AF $(\mathrm{cm})$ & PF $(\mathrm{g})$ \\
\hline 0,00 & $4,03 \mathrm{~b}^{*}$ & $5,80 \mathrm{~b}$ & $2,33 \mathrm{a}$ & $5,25 \mathrm{~b}$ & $8,55 \mathrm{~b}$ \\
0,25 & $5,12 \mathrm{ab}$ & $7,61 \mathrm{ab}$ & $2,42 \mathrm{a}$ & $5,75 \mathrm{~b}$ & $8,75 \mathrm{~b}$ \\
0,50 & $6,85 \mathrm{a}$ & $8,85 \mathrm{a}$ & $2,67 \mathrm{a}$ & $6,25 \mathrm{a}$ & $9,55 \mathrm{a}$ \\
\hline
\end{tabular}

*Médias seguidas por letras distintas na coluna diferem entre si pelo teste de Tukey a 0,05 de significância

$\mathrm{Na}$ característica comprimento de folha observamos que também houve diferença entre as médias com relação à dose de $0 \%$ das algas, onde as doses de 25\% e 50\% apresentaram valores de 7,61 e 7,55 respectivamente. Biasi (2002) pode estar associado à presença de algum fitohormônio ou regulador de crescimento que possa estar presente no biofertilizante, pois essas substâncias atuam no crescimento e desenvolvimento de plantas. Já para a cultura da alface foi possível identificar diferença estatística em todas as doses do biofertilizante a base de algas, para todas as características (Tabela 3).

Para todas as características na cultura da alface a dose do biofertilizante a base de algas de 25\% e $50 \%$ proporcionaram maiores desenvolvimentos inicial (Tabela 4). Os resultados obtidos no trabalho, vem de encontro com o estudo de Costa et al., (2018), trabalhando com biofertilizante a base de esterco bovino, para quatro cultivares de alface, encontraram resultados superiores ao tratamento controle, 
destacando o comprimento das raízes $(5,50 \mathrm{~cm})$ como

um dos melhores resultados.

Tabela 3. Valores de $\mathrm{p}$ - probabilidade para as variáveis de comprimento de raiz (CR), altura de planta (AP), número de folhas $(\mathrm{NF})$, área foliar $(\mathrm{AF})$ e peso fresco $(\mathrm{PF})$ no desenvolvimento inicial da cultura da alface (Lactuca sativa L.) em diferentes doses de biofertilizante a base de algas. 15 DAE.

\begin{tabular}{lccccc}
\hline FV & CR $(\mathrm{cm})$ & AP & NF & AF & PF \\
\hline Doses do biofertilizante & $0,000^{*}$ & $0,0023^{*}$ & $0,0134^{*}$ & $0,0001^{*}$ & $0,0015^{*}$ \\
\hline CV\% & 11,53 & 11,12 & 17,37 & 10,86 & 9,88 \\
Média geral & 5,73 & 7,81 & 3,69 & 8,75 & 10,25 \\
\hline
\end{tabular}

Valores de $\mathrm{p},\left(^{*}\right)$ significativo pelo teste $\mathrm{F}$ ao Nível de $5 \%$ de probabilidade, (ns) não significativo

Amorin Neto (2019) trabalhando com produção de mudas de tomateiro e biofertilizante a base de extrato de alga, verificou que de acordo com o comprimento radicular e total, o tratamento composto por plantas tratadas com 2,5\% de extrato de alga, se destacou estatisticamente em relação as demais. Em relação ao comprimento da parte aérea, o tratamento composto por extrato de algas a dose de $7 \%$, se destacaram entre os demais tratamentos e obteve um aumento de 82,93\% em relação a testemunha.

Segundo Fernandes et al. (2011), vários trabalhos na literatura demonstram que produtos à base de extrato de algas apresentam importantes funções na planta, das quais se destacam a atividade citocínica (aumento na divisão celular e mais controle do fruto), a atividade auxínica (controle do crescimento do caule), a atividade giberelínica (elasticidade e plasticidade da célula) ebetaínas (reduz estresses relacionados à água e rupturas). Este fato, justifica os resultados obtidos neste trabalho, praticamente o biofertilizante a base de extrato de alga, nas duas concentrações 0,25 (25\%) e $0,50(50 \%)$ apresentaram efeito positivos em relação ao tratamento controle (Tabela 04). Segundo Luz et al. (2010), a aplicação de fertilizantes foliares proporcionam resposta positiva sobre a produção de alface, chegando a cultura apresentar seu potencial máximo.

Tabela 4. Comprimento de raiz (CR), altura de planta (AP), número de folhas (NF), área foliar (AF) e peso fresco (PF) no desenvolvimento inicial da cultura da alface (Lactuca sativa L.) em diferentes doses de biofertilizante a base de algas. $15 \mathrm{DAE}$

\begin{tabular}{lccccc}
\hline Doses do biofertilizante & CR $(\mathrm{cm})$ & AP & NF & AF & PF \\
\hline 0,00 & $5,50 \mathrm{~b}^{*}$ & $7,25 \mathrm{~b}$ & $3,50 \mathrm{~b}$ & $7,67 \mathrm{~b}$ & $9,25 \mathrm{~b}$ \\
0,25 & $5,16 \mathrm{~b}$ & $7,62 \mathrm{~b}$ & $3,42 \mathrm{~b}$ & $7,89 \mathrm{~b}$ & $10,55 \mathrm{ab}$ \\
0,50 & $6,54 \mathrm{a}$ & $8,57 \mathrm{a}$ & $4,17 \mathrm{a}$ & $8,55 \mathrm{a}$ & $11,25 \mathrm{a}$ \\
\hline
\end{tabular}

*Médias seguidas por letras distintas na coluna diferem entre si pelo teste de Tukey a 0,05 de significância

Os resultados encontrados no presente estudo são relevantes, comprovando a ação positiva do biofertilizante a base do extrato de alga quando aplicado na planta e no substrato, considerando que as raízes proporcionam a absorção de nutrientes, influenciando diretamente no desempenho final das plantas (FERRAZ et al. 2005; MINAMI, 1995; SILVEIRA et al., 2002).
Veronka et al. (2008) utilizando o biofertilizante formulado "Supermagro" encontrou resultados inferiores de altura de planta $8,2 \mathrm{~cm}$ e Medeiros et al. (2007) 5,26 cm avaliando o desenvolvimento de mudas de alface sob efeito de diferentes biofertilizantes na adubação foliar. Para número de folhas Freitas et al. (2019) encontrou resultados superiores de 5,6 folhas plântula-1, avaliando 
a aplicação do Fertilizante Organomineral Núcleo® na produção de mudas de alface.

O número de folhas da alface e a altura da planta podem estar relacionados às funções que o biofertilizante exerceu sobre as propriedades físicas, químicas e biológicas do substrato, uma vez que eles aumentam a capacidade do solo em armazenar nutrientes necessários ao desenvolvimento das plantas (OLIVEIRA et al., 2018). Esses resultados apontam que a aplicação do biofertilizante como fonte de nutrientes às hortaliças, no estágio inicial do seu desenvolvimento é uma alternativa que traz benefícios para o seu desenvolvimento, mas, cada cultivar pode responder de forma diferente, dependendo da sua necessidade.

\section{Conclusão}

O biofertilizante a base de alga proporcionou melhor desenvolvimento para às plântulas de alface na concentração de 50\%. Para as plântulas de rúcula o recomendado é a utilização na concentração de $25 \%$.

\section{REFERÊNCIAS}

ALVES, I.A; SANTOS, S.M. Avaliação dos efeitos do uso do silício e do zinco no cultivo de rúcula em sistema de produção hidropônico. Trabalho de Conclusão de Curso. Agronomia. Centro Universitário Unisalesiano. 63p. 2018

AMORIM NETO, A.F. Produção de mudas de tomate com extrato de algas marinhas. Trabalho de Conclusão de Curso. Agronomia. Centro Universitário de Anápolis - Unievangélica. 27p. 2019.

ARAUJO, O. K. W; DIAS, S.R.; FERREIRA, J. D.; SANTOS,L. R. A produção de hortaliças pela agricultura familiar. XXI encontro nacional de geografia agrária. Uberlândia, v. 1, p. 1-2, 2012.

BIASI, L.A. Reguladores de crescimento vegetal. In: Wachowicz, C. M.; CARVALHO, R. I. N. de.
Fisiologia Vegetal: Produção e Pós-colheita. Curitiba: editora Champagnat, p. 115-134, 2002.

BONETT, L.P; OLIVEIRA, K.M; KABAYASHI, G.H; GINO, B.G; MAGALHÃES, H.M; CRUZ, R.M.S. Produtividade da alface cv. Isabela ${ }^{\circledR}$ sob aplicação de fontes e doses de fertilizantes líquidos. Colloquium Agrariae, v. 15, n.4, p. 74-81, 2019.

BRITO, F. Produção de tomate (Solanum lycopersicum L.) reutilizando substratos sob cultivo protegido no município de Iranduba-AM. 2017. Disponível em:

https://ainfo.cnptia.embrapa.br/digital/bitstrea $\underline{\mathrm{m} / \text { item/80343/1/BritoJr-prod-tomate.pdf }}$

COELHO, R.N.C; AGUIAR, C.A.C; SILVA, C.F; NÓBREGA, T.F; PEREIRA, J.R; FERREIRA, J.D; ALMEIDA, B.A.S; ARAGÃO, C.A. Uso de extrato de algas marinhas na produção de mudas de pimentão. Horticultura brasileira, v. 30, n. 2, (Suplemento - CD Rom), julho 2012

COSTA, A. C.; RODRIGUES, M. L; VASCONCELOS, L. C.; GARCIA, R. V.; CARVALHO, A. H. O.; LIMA, W. L. Biofertilizante de esterco bovino na produção de mudas de alface. Anais do VI CLAA, X CBA e V SEMDF - v. 13, n 1, 2018.

COSTA, C. A. 1994. Crescimento e teores de sódio e de metais pesados da alface e da cenoura adubada com compostos orgânicos de lixo urbano. Viçosa, MG. UFV, 89 p. (Tese mestrado).

DELEITO CSR; CARMO GF; ABBOUND ACS; FERNANDES MCA. 2000. Sucessão microbiana durante o processo de fabricação do biofertilizante Agrobio. In: FERTBIO 2000. Santa Maria, RS: Sociedade Brasileira de Ciências do Solo e da Sociedade Brasileira de Microbiologia.

FERRAZ, M. V.; CENTURION, J. F.; AMAURI, N. B. Caracterização física e química de alguns substratos comerciais. Acta Scientiarum Agronomy. v. 27, n. 2, p. 209-214, 2005.

FERREIRA, D. F. Sisvar: a computer statistical analysis system. Ciência e Agrotecnologia, v. 35, n. 6, p. 1039-1042, 2011. 
FERREIRA, M. M. A. A. S.; SOUZA, G. S.; SANTOS, A. R. Produção de mudas de rúcula em diferentes substratos cultivadas sob malhas coloridas. Enciclopédia Biosfera, Centro Científico Conhecer - Goiânia, v.10, n.18, p. 2.429-2.440, 2014.

FILGUEIRA, F.A.R. Novo manual de olericultura: agrotecnologia moderna na produção e comercialização de hortaliças. 3 ed. Viçosa: UFV, 2008. 421 p.

FREITAS, A. P.; SILVA, A. B.; SANTI, A.; MAGALHÃES, M. O. L.; SILVA, G. B. Produção de mudas de alface em substrato sob doses de fertilizante organomineral. Enciclopédia Biosfera. v.16, n.29, p. 2, 2019.

GARCIA, KAIO; SILVA, CILLAS; CUNHA, CLEYTON; NASCIMENTO, CARLA; TOSTA, MAURO. Extrato de algas Ascopbyllum nodosun (l) no desenvolvimento de porta enxerto de cajueiro. Enciclopédia biosfera, centro cientifico conhecer - Goiania, v.10 n¹8 p. 1706, 2014.

GUERRERO, A. C.; BORGES, L. C.; FERNANDES, D. M. Efeito da aplicação foliar de silício em rúcula cultivada em dois tipos de solos. Biosci. J., Uberlândia, v. 27, n. 4, p. 591-596, 2011.

LUZ, J.M.Q.; OLIVEIRA, G.; QUEIROZ, A.A.; CARREON, R. Aplicação foliar de fertilizantes organominerais em cultura de alface. Horticultura Brasileira, v.28, n.1, p.373-377, 2010.

MACEDO, R. O uso de algas marinhas na agricultura. 2016. Disponível em: https://www.agrolink.com.br/colunistas/colun a/o-uso-de-algas-marinhas-na-agricultura388103.html Acessado em: 15/02/2021.

MALAVOLTA, E. (Manual de nutrição mineral de plantas). São Paulo: Ceres, 2006. 638p.

MEDEIROS, D. C.; LIMA, B. A. B.; BARBOSA, M. R.; ANJOS, R. S. B.; BORGES, R. D.; CAVALCANTE NETO, J. G.; MARQUES, L. F. Produção de mudas de alface com biofertilizantes e substratos. Horticultura Brasileira. v. 25, p.433-436, 2007.

MEDEIROS, J. F.; SILVA, M.C.C.; SARMENTO, D.H.A.; BARROS, A.D. Crescimento do meloeiro cultivado sob diferentes níveis de salinidade, com e sem cobertura do solo. Revista Brasileira de Engenharia Agrícola e Ambiental, v.11, n.3, p.248-255, 2007.

MINAMI, K. Produção de mudas de alta qualidade em horticultura. São Paulo: T. A. Queiroz, 1995, 128 p.

OGAWA, J. M. O uso de biofertilizantes no controle de pragas da cultura do alho. Monografia (graduação em Agronomia) - Universidade Federal de Santa Catarina, Campus Curitibanos, Curitibanos, 17f., 2012.

OLIVEIRA, R. C.; SILVA, J. E. R.; AGUILAR, A. S.; PERES, D.; LUZ, J. M. Q. Uso de fertilizante organomineral no desenvolvimento de mudas de rúcula. ACSA, v.14, n.1, p.1-6, 2018.

PAULA JÚNIOR T. J.; VENZON M. Culturas: manual de tecnologias agrícolas. Belo Horizonte: EPAMIG. 2007, 800 p.

PEREIRA, M. A. B.; SILVA, J. C.; MATA, J. F.; SILVA, J. C.; FREITAS, G. A.; SANTOS, L. B.; NASCIMENTO, I. R. Uso de biofertilizante foliar em adubação de cobertura da alface cv. Verônica. Pesquisa Aplicada \& Agrotecnologia, v3, n2, 2010.

PINTO, P.A.C; SANTOS, N.G.N; GERMINO, G.F.S; DEON, T.D; SILVA, A.J. Eficiência agronômica de extratos concentrados de algas marinhas na produção de alface em Neossolo Flúvico. Horticultura brasileira, v. 28, n. 2 (Suplemento - CD Rom), julho 2010.

RESENDE, G.M.; ALVARENGA, M.A.R.; YURI, J.E.; SOUZA, R.J. Rendimento e teores de macronutrientes em alface americana em função de doses de nitrogênio e molibdênio. Horticultura Brasileira, v.30, n.1, p.373-378, 2012

SANTOS, NGN; PINTO, PAC; SILVA, AJ; MARQUES, RS; SANTOS, SA. 2011. Eficiência de doses de fertilizante organomineral à base de extratos concentrados de algas marinhas na formação de mudas de tomate IPA-6 no município de Juazeiro-BA. In: CONGRESSO BRASILEIRO DE OLERICULTURA, 51. Anais... Viçosa: ABH. 
SILVEIRA, E. B. et al. Pó de coco como substrato para produção de mudas de tomateiro. Horticultura Brasileira, v. 20, n. 2, p. 211-216, 2002.

SOBREIRA FILHO, M.G. Manual de cultivo das hortaliças em horta doméstica, educativa e comunitária. Recife: 2012. 84p

STEINER, F.; PIVETTA, L. A.; CASTOLDI, G.; PIVETTA, L. G.; FIOREZE, S. Revista Brasileira de Ciências Agrárias.v.6, n.2, p.230235, abr.-jun., 2011.
VERONKA, D. A.; SILVA, J. F.; OLIVEIRA, J. H.; RODRIGUES, A. P. D. A. C.; LAURA, V. A.; PEDRINHO, D. R. Uso do biofertilizante na produção de mudas da alface. Horticultura Brasileira. v. 26, p.1168-1171, 2008.

VIDAL, V. M.; MARCOLA, R. R.; VALÉRIO, F. L.; OLIVEIRA, G. G.; BARCELOS, H. F.; SILVA, P. C. Aplicação de diferentes doses do biofertilizante urina de vaca na produção de mudas de rúcula. VI JORNADA ACADÊMICA, Unidade Universitária de Santa Helena de Goiás, 2012. 